


\title{
Notes on the vocalizations of Shining Sunbird (Cinnyris habessinicus)
}

Peter Boesman

In the following we briefly analyze and compare voice of the different races of Shining Sunbird (Cinnyris habessinicus). We also try to quantify the extent of any vocal differences using the criteria proposed by Tobias et al. (2010), as a support for taxonomic review.

We have made use of sound recordings available on-line from Xeno Canto (XC) and Macaulay Library (ML).

Our main interest is to compare voice of the two races from the Arabian peninsula (kinneari, hellmayri) with the races on the African mainland.

There are very few recordings available of the Arabian taxa:

A single recording of kinneari has some 'chup' call notes.

Recordings from Oman (hellmayri) are mainly 'chup' calls, but the following two seem to have a song-like vocalization:


These phrases consist of nearly identical repeated notes, with most of the power in the range $3-5 \mathrm{kHz}$.

This vocalization type is quite different from any recording from Ethiopia of song-like vocalizations (nominate and turkanae). Song here seems to be a short usually descending series of notes, sometimes combined with grating notes and/or stuttered series.

Some examples:
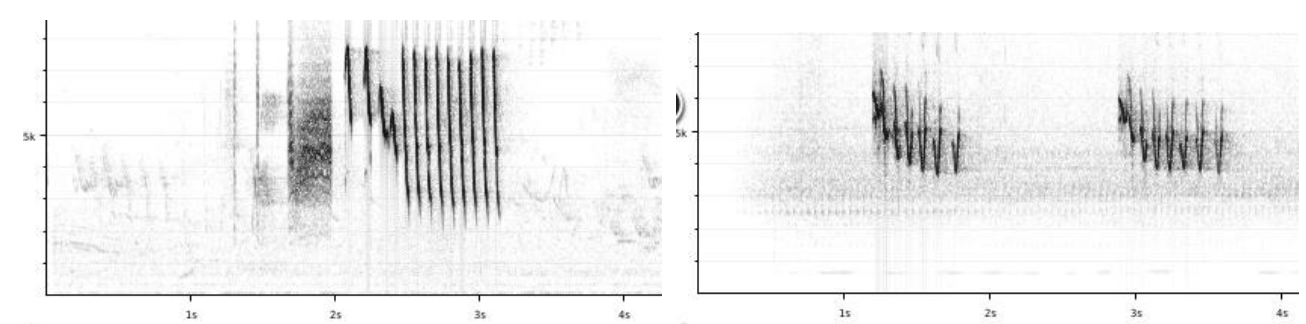

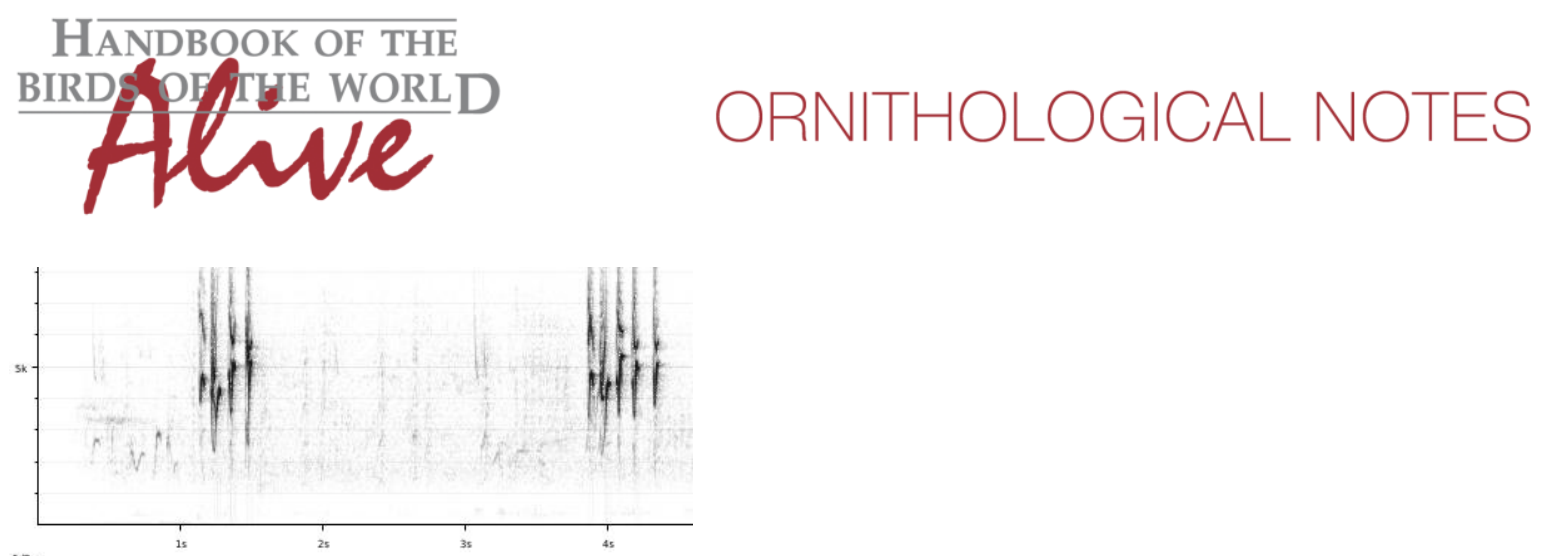

Given there are only few recordings available for all taxa, it is likely that the full vocal repertoire is more extensive than what we can deduct from present evidence. If we assume that the above song-like vocalizations are homologous, then for hellmayri it is lower-pitched with a narrower frequency range (2), consisting of mainly identical notes (2) which have a different note shape. It is quite obvious however that we need more recordings to confirm such difference.

This note was finalized on 25th April 2016, using sound recordings available on-line at that moment. We would like to thank in particular the sound recordists who placed their recordings for this species on XC: Peter Boesman, Oscar Campbell, Phil Gregory, Ben King, Linda Macaulay, Hans Matheve, Andrew Spencer and Herman van Oosten.

\section{References}

Tobias, J.A., Seddon, N., Spottiswoode, C.N., Pilgrim, J.D., Fishpool, L.D.C. \& Collar, N.J. (2010). Quantitative criteria for species delimitation. Ibis 152(4): 724-746.

\section{Recommended citation}

Boesman, P. (2016). Notes on the vocalizations of Shining Sunbird (Cinnyris habessinicus). HBW Alive Ornithological Note 340. In: Handbook of the Birds of the World Alive. Lynx Edicions, Barcelona. (retrieved from http://www.hbw.com/node/1252799 on 25 October 2016). 